\title{
Reflexivity as a Process for Coming Into Knowing
}

\author{
Karen McGarry
}

\begin{abstract}
Acting reflexively implies a "self-critical and self-conscious stance" (Glass, 2015, p. 555) of recognizing myself within a research process as an intentional participant-practitioner of generating knowledge. This article attempts to reveal visual evidence across a landscape of textual references and material implementations as a process of the what and how of knowing. My aim is to affirm the intentionality of my reflexive praxis as a way of knowing and becoming through committed intertextual inquiry and discovery. ${ }^{1}$
\end{abstract}

\section{Reflexivity as a Process for Coming Into Knowing}

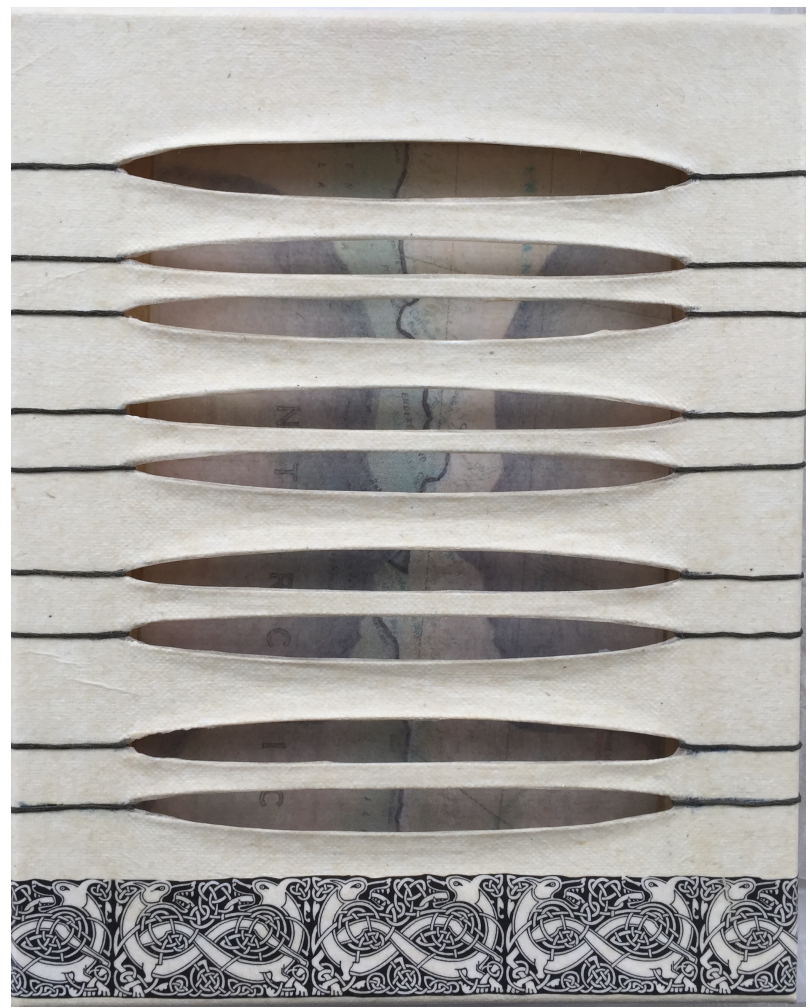

Fig. 1: What if I look inside? April 2018, mixed media on canvas, 8 × 10 in.

My portrait reveals and conceals an identity at times struggling to find a place of acceptance and understanding for an unconventional reflexive praxis. The two facial profile images represent aspects of one identity-one working within acceptable limits and expected practices, and the other engaging in an alternative, less predictable manner. Set beneath the canvas surface, the two identities peel away at ideas, uncovering concepts related to intentional discovery. Looking inside is how I might learn to know, opening a door to potential believability and play as a site for intertextual becoming. 
What if I look inside? Both figuratively and literally? What does a researcher look like; is there "an identity" encapsulating a researcher and what they might look like? Not a literal look, of course, but a figurative one: an attempt to envision what the processes of researching, thinking, pondering, puzzling might look like if it could be observed and examined. As an arts-based researcher, I often find myself outside the scope of the traditional research practices of statistical significance, sample sizes, and generalizable outcomes. Resultingly, I am regularly in a position of needing to defend, define, or explain my work as research. For those unfamiliar with arts-based research, it is understandable to question such practice, and search for how, as a practitioner, I can call such training "research," especially when it assumes such an unlikely façade. An arts-based researcher utilizes transdisciplinary and intertextual approaches to investigate a research question or hypothesis (Leavy, 2015), a process that can detour from traditional qualitative or quantitative research. Even within arts-based research there are subtle distinctions and classifications for inquiry practice. For example, within arts-based inquiry methods, there is an additional classification of research practice known as $A / r /$ tography, blending the practices of artist/researcher/teacher into one investigative body. As an artist and an educator, my methods share in this distinction, yet, as Leavy posits, the "umbrella category" (p. 5) of arts-based research/researcher can be assumed by this author, in this article, since my professional persona envelops all three identities. No matter the classification, central to this argument is the appreciation that, in arts-based research, the arts are fundamental and significant to the research process, and the contributions these practices provide are intentional and generative.

The arts are often used to bolster research practice, as a method of evoking ideas that can then begin conversations (Eisner, 2012). These conversations then might lead to an actual research process following either qualitative or quantitative methods, for example. In such a process, the arts can be supportive, even instructive, for informing how to approach a research topic or question. For me, however, the arts are not a method of informing my research-they are an intentional pathway of my research. In Art as Experience, John Dewey (1934) wrote: "Mountain peaks do not float unsupported; they do not even just rest upon the earth. They are the earth in one of its manifest operations" (p. 2). Whether digging below the surface or building upon one, my research reveals a deliberate investigative pathway of discovery, lucidity, and an elicitation that guides knowledge acquisition. Through arts-based inquiry, research questions find answers that often lead to further questioning and discovery, yet these processes generate owned or embodied knowledge, gleaned through a self-reflexive experiential praxis as a process of becoming.

This article attempts to reveal a glimpse into an arts-based research process literally, by locating the research in methodologies and philosophical positions that can illuminate how my work is generated, and figuratively, by revealing examples of a reflexive process of inquiry across a landscape of textual references and material implementation. My aim is to show what my research might look like and to affirm the intentionality of my reflexive praxis as a way of knowing. 


\section{What Am I Trying to Study?}

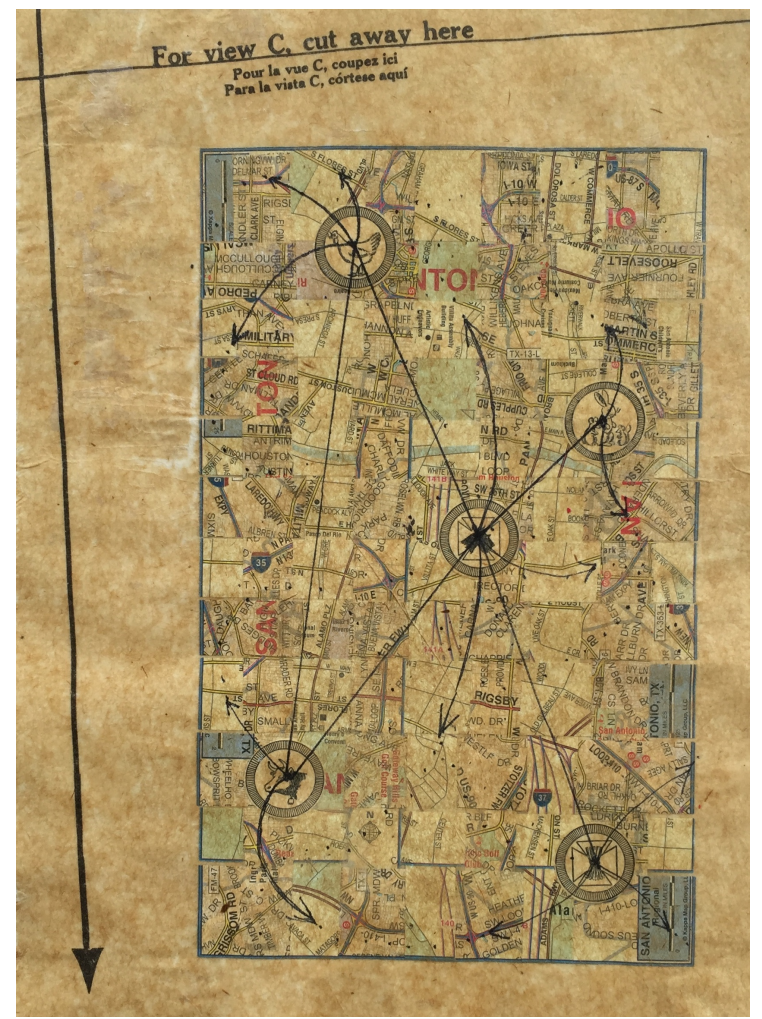

Fig. 2: Mapping a terrain without a map. February 2018, mixed media collage on paper, 7 × 10 in.

Mapping out a direction can be daunting, especially if you've lost your way or don't know where you are. Like a dérive, you meander through a place with a foreign map. It looks right. It has streets and locator dots for cities and sites of special interest. But you are not there. While struggling to understand your setting, you come upon new venues, like those already familiar, yet decidedly different. The experience is awakening, enlivening. You decide to stay, to use your mapping system as an adventuring guide for an undetermined destination.

Thomas Kuhn (1962) wrote his scientific revolutions book the year I was born. I did not read it until I was 30 years old; it shifted my learning process and my thinking about knowing. It was the first time I read the word paradigm and it began a long, iterative process of reading and writing with a dictionary companion. Kuhn's notions are sticky and complex, yet I refer to his words often because they scaffold a framework for organizing my thoughts. My own paradigm is messy and incomplete, evolving from contemplating experiences (reflection), seeing myself as a part of those experiences (reflexivity), and framing the experiences in some form-a story or narrative, a body of research, a book, sculpture or drawing-to make meaning happen (praxis).

Presently, my paradigm is like a map with connecting, meandering roads dotted with place names. Sometimes the roads intertwine or meld into each other, other times they veer off and avoid contact. The place names comprise a list of ideas that continually percolate and remind, morph and renew. Some of these place names include: believability, bricoleur, dialogism, discourse, equality, equity, feminism, gesture, identity, intersectionality, narrative, play, praxis, professionalism, reflection, 
reflexivity, subjectivity, symbols, teachers, touch, utterances, visual, and voice. This simmering list nests inside my paradigm, waiting for discovery to reveal an interconnected purpose and "after a revolution," to "work in a different world" (Kuhn, 1962, p. 135). One such world may develop at the intersection of gesture, utterance, and voice, and reveal a pathway of knowing that crosses textual distinctions to illustrate the what and how of communication through varied expressive systems. And what might happen at the intersection of symbol and believability, or equity and discourse? These imaginable intersections await, even beckon, and invite knowing.

My inquiry process often begins with an invitation to know more. A word or an idea from a book or an article may ignite a desire for creative exploration. For example, the map image in Figure 2 reflects the notion of the dérive as proposed by Guy Debord in 1956 (Knabb, 1995). I was interested in expanding on Debord's theory of drifting, wanting to create an image that would interrupt and confuse any natural drift for the sake of visual patterning. This image started by cutting a map page into narrow strips and then weaving them together, negating the functionality of the map face. Over the woven map, I placed images of badge symbols cut from a Girl Scout's Handbook (Girl Scouts of the United States of America, 1955) depicting animals and agriculture and adhered them to the surface, locating positions on the map face as points of interest or large cities. Over the entire page, I adhered a piece of dress pattern paper as a translucent layer to both mask the surface and create a uniform appearance. Then, I drew lines connecting badge sites to propose paths, or ways to know this image by suggesting directions or guidelines, visually mapping the image's surface. As I reflect on the image, the compositional elements appear to drift across the surface and suggest possible narrative interpretations of a process. I imagine a potential viewer wondering about the envisioned communicative intent and how the artist constructed a story-like model inscribed with meaning. The image locates a place to ponder, without a key or a clue toward a specific reading, but offering a site potentially uncovering an archetype for learning to inquire about knowing.

Kuhn (1962) speaks to the notion of a paradigm as "an accepted model or pattern" (p. 23), shared as an understanding of a process or state. Arts-based research, for example, might represent a model of a communicative method. As a state of communication or being, a paradigm has potential to describe, inform, and evolve through processes of reformulation or retrofitting. A revolution in a paradigm occurs when there is an incompatibility within paradigm states (p. 93), enough to suggest an evolutionary development that results in a paradigmatic shift in knowing and understanding. In art education, for example, Discipline Based Art Education (Delacruz \& Dunn, 1996), introduced in the 1980s, represented a shift in the formal processes of teaching and learning in the arts, partly in response to the increasing need for accountability and evaluation of student learning in all discipline structures. This shift, and others like it, necessitates a new mapping system, pathway, or plan that can represent how a new paradigm might be conceptualized. Similarly, mapping a learning trajectory may offer insight toward the what and how of a research plan as a communicative device for developed knowing as one moves between paradigms equipped with new information or insight. In positing the question, "What am I trying to study?", my aim is to map a plan of action that investigates how knowing is revealed through a series of query points and connecting lines that consider an intent for knowing. 
The visual variations within my arts-based inquiry methods, reveal multiple pathways toward knowing, introducing new knowledge reflecting alternative paradigms as constructive, even awakening.

Such a constructive action plan may disclose potential benefits for arts-based inquiry as a generative process of reflexivity and informed praxis for teacher education, for example, emphasizing mapping inquiry as centered in embodied knowing. Could this embodied knowing generate active reflectionreflexivity - as illustrated in Figure 2? Might teacher education become a site for bridging learning across and through texts, each part scaffolding the next, blending their edges until they share a compositional framework of inquiry toward informed knowing? By creating reflexive visual texts, I begin to construct parts of an artist/researcher/teacher identity through overlays of guiding information generating potential pathways of knowing. The overlay information consists of materials and ideas intersected by choices and decisions to articulate intentional praxis. Using the overlays as guides to map a professional identity may reveal an educator who is open, present, and responsive to individual experiences of the self and of others. Within connected praxis, identity formation may be revolving as an emerging paradigm, always already becoming.

\section{What Helps to Guide Research?}

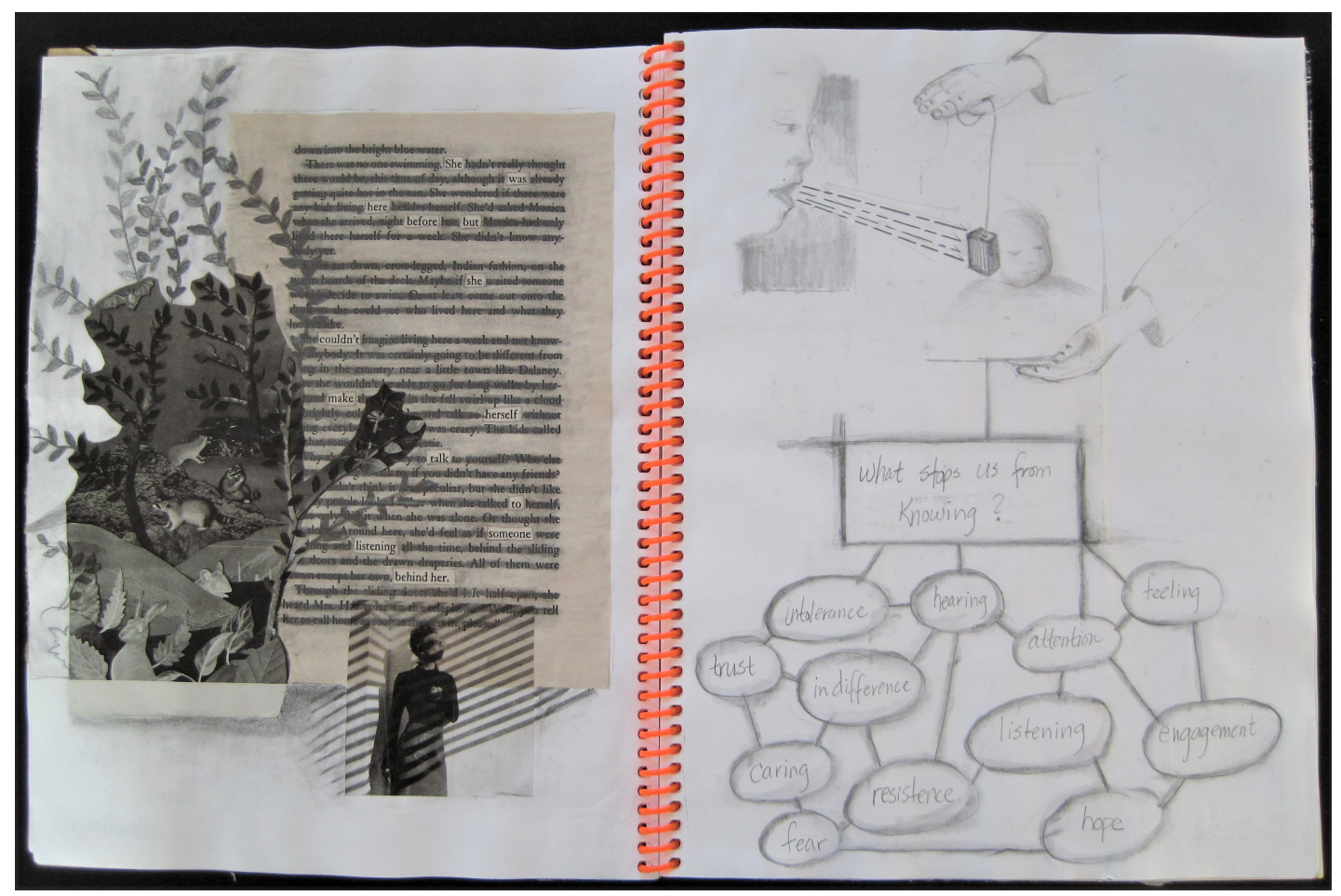

Fig. 3: Choosing to participate. April 2018, watercolor, pencil, and collage on paper, $16 \times 11$ in.

Words heard, seen, written, spoken, all have the potential to instigate response. Whether we make the choice to participate in dialogue is another issue and one we wrestle with in daily dialogic negotiations where we reveal and conceal, express and share, or redact information depending on our level of participatory engagement. 
Just like written or spoken language, visual language is learned and taught, enhanced, even mastered, through practice, repetition, and committed application; it can act as a guide toward knowing. In making images or objects, I come to know and understand my experiences within a process of discovery and learning. The tools incorporated during making are often familiar and direct-they allow me to communicate through a known tongue, realized through explicit engagement and use, learned over and through time. The materials selected, reveal a voice or dialect, sometimes soft or subtle and other times stern or focused, for communicating ideas uncovered in a research process. They become the phenomena that reveal and guide my sense of self within an active, creative process as experiential knowing.

Aspects of knowing that extend from participation within dialogic encounters, highlight the intent of Figure 3. The two-page spread illustrates visual and verbal communication across the spiral binding. The left side began with a found poem - a device for constructing prose out of a page of text through redacted mark-making. The found poem describes a failed encounter for potential dialogic interaction with others: "She was here before, but she couldn't make herself talk to someone listening behind her." The words selected reinforce the participative qualities of engaged dialogue, or a lack thereof. The overall collage locates the poem between two magazine photographs, one depicting an animal diorama and the other, a woman in a dramatically lit interior. Both photographs supported my use of drawing to extend the features of foliage and of cast shadows to blend background with foreground: the foliage is drawn to cover or connect the lines of redacted text, while the cast shadows mimic the graphite lines used to redact the unessential words on the page. The intention was to equate listening as an overlapping and interconnected process of any dialogic encounter, as depicted more directly, or graphically, in the opposite page positing the question: What stops us from knowing? Here the intent was to show how dialogue may be halted by external forces, suggesting a web of words that may both deter or enhance a sense of knowing, depending on personal subjectivities or experiences. By selecting collage and graphite, my intent aimed at revealing my personal inner dialogue as a dialectic phenomenon.

Phenomenology, according to Hammersley (2012), refers to how we see or know things as related to our experiences or "how people see or experience themselves in their world" (p. 9). The dialogue produced between myself as maker, the object as product, and the viewer as a participant, helps to shape an experience and offer a pathway of knowing within my world. Elliot Eisner (2012) once wrote, "Knowledge creation is a social affair" (p. 11); it is a process of knowing that arts educators can tap into multidisciplinary dialogue between modes of learning, knowing, researching, becoming. Educators can establish lasting partnerships of participatory activity with other education colleagues that dispel and negate learning silos, moving toward interconnected sites of learning that honor ways of knowing in social contexts. Learning in and between disciplines extends knowing into a "transdisciplinary" realm, as Cindy Foley discussed in a TED talk (2014), aiming to reinforce how we come to know and appreciate learning pathways when the potential for understanding includes multiple tracks for knowing content (McGarry, 2018). Content, which may be mere ideas or thoughts surrounding certain phenomena, strives to wrestle a conceptual premise or framework for knowing by thinking across and through embodied knowledge toward becoming. 
My reflexive making processes center on deliberation of concepts stemming from a postmodern, experiential phenomenological framework. Contemplation is both vital and significant within a postmodernist approach to knowing, and it has the potential to value ideas or concepts that often surpass finished products (Encyclopedia of Art, 2018). This postmodern practice relies on a method that places value on informed and intended praxis-ideas are considered, researched, and argued, and, the application of making methods stems from an intentional and deliberate code of material knowledge. The works exist on a transmediated plane-traversing written, spoken, and visual languages-all interlinked through the contemplative process. A postmodern philosophy also requires a "multilingual" (Eisner, 2012, p. 10) methodology for revealing a learning process through constructive media manipulation, coupled with levels of subjectivity (Heron \& Reason, 1997), recognizing ourselves in context: a reflexive realization of knowing. Within that realization, however, lies a supporting cast of frameworks whose mission it is to ground, sustain, and provide context for how those pathways toward knowing are shaped, formed, and preserved.

\section{How Are These Guides Supported?}

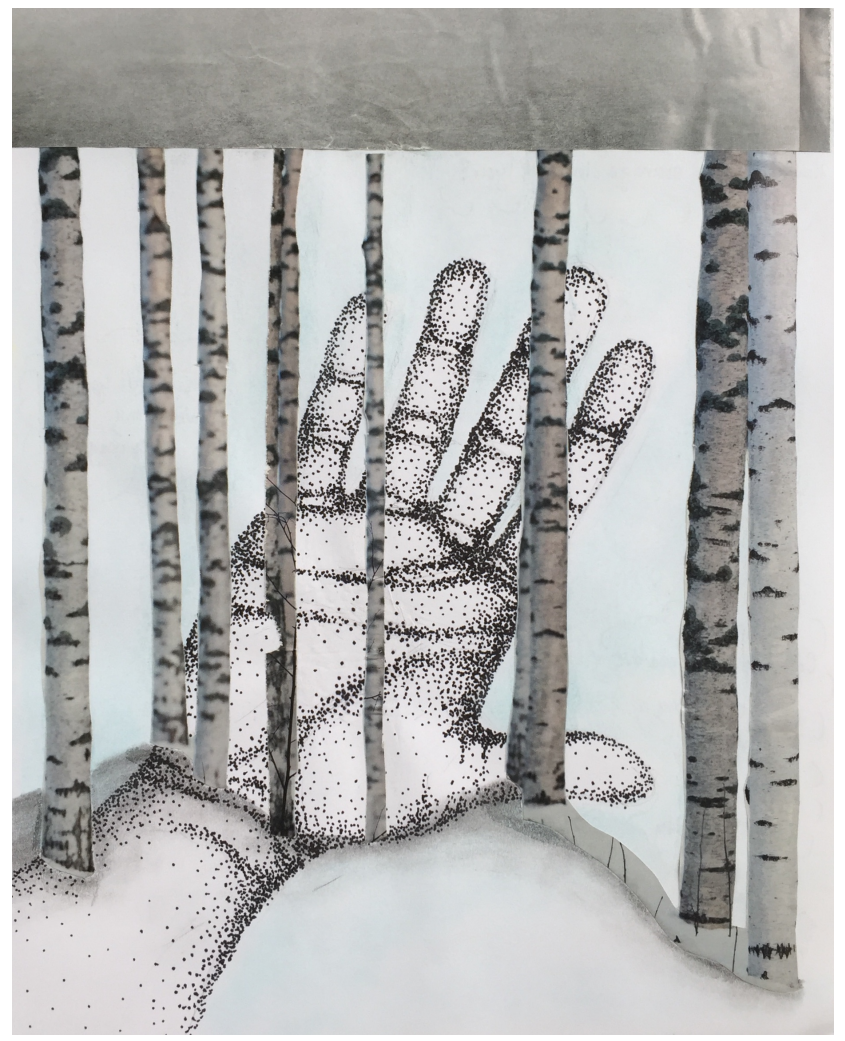

Fig. 4: Can I see my hand for the trees? February 2018, mixed media collage on paper, 8 x 9 in.

That's what makes guides so tricky-you never know if you can trust them and if you do extend that trust, how far are you willing to commit? Sometimes guides impair clarity and obscure the very thing you are trying to see. Other times, they offer a sense of direction, a pathway toward endurance. Choosing to blend methods of guidance can achieve enhanced visibility and even facilitate affirmation and trust in the process-your process. 
If I identify within a postmodernist phenomenological framework, how does this stance inform my identity as an arts-based researcher? A postmodern stance suggests an identity as a "meta-symbol through which we construct and reconstruct our version of the world" (Rolling, Jr., 2013, p. 132). Through any process of construction or re/deconstruction, I gain knowledge by experiencing phenomena in my world. Therefore, these philosophical guides appear interlinked, conjoined in an action of assembled meaning making and, as suggested by Michael Crotty (1998), "meaning is not discovered but constructed" (p. 9), potentially through engagement in a knowing process. Constructionism offers a view of reality that is assembled through experiences shaped by interaction with individual societies and cultures that use symbols to name and resource ideas. Arts-based research expands how symbols communicate within a context of ideas assembled to reflect personal, social, and cultural significance.

In assembling the image in Figure 4, the first marks I made on the page were the dots that eventually stippled the shape of a hand. I chose to draw a hand to reference the direct association between markmaking and the artist's hand; however, as I am right-handed, and the drawing is of a right hand, the drawing might suggest that this is not my hand image on the page, but one drawn from a photograph or from a model. There is a dialectic at play in this image between a depicted reality and an artist's intent. The image title reflects this dialectic: in asking if I can see my hand for the trees, I highlight the tension at play within the elements in the composition. The title also reflects a play on the familiar saying of, "you can't see the forest for the trees," whereby someone so mired in the detail of a situation, neglects the bigger picture at stake (Cambridge Dictionary, 2018). By invoking that title, I may be intimating at my technical over-focus on detail while overlooking the composition as a whole. Creating an image with the stippling technique is consuming of both time and attention: it is easy to lose yourself in the meditative process of making tiny dots on a page, while being swept along in the flow. Adding to the dialect of the composition, are the collaged tree images. The tree images are cut from a larger magazine page, removing specific trees from a forest of trees. Because these fragments are printed in a magazine, the printing process creates images from small, color dots that our eyes and brains can understand once the image is printed on a page. If the tree images were magnified, however, their shape and color would reveal those small dots, much like the stippled dots created by my hand in the drawing portion of the composition. Therefore, as a composition, Figure 4 reveals the same technique used to create a visual reality-dots. Constructing my image through my material language, generates a postmodern view of a reality born from different processes of textual knowing as arts-based research.

A postmodernist identity understands knowing through seeing as part of an intertextual experience (Rolling, Jr., 2013), and one that develops, or is constructed, through interaction with and within multiple texts, from varying media sources. This gleaned knowledge and understanding expands to meet the conceptual space it is provided, without restraints on creative, imaginative curiosity, suggesting a pragmatic appreciation for knowing. Though traditional views of pragmatism often reflect the work of John Dewey and Charles Sanders Peirce, more contemporary voices like Richard Rorty's argue that a role of pragmatism is to free knowledge from formal views that can constrain and limit philosophical imaginings (Ramberg, 2009). Such a view of pragmatism may open understanding of knowledge as a 
shifting, emergent phenomena: a becoming or an understanding and appreciation for learning gathered through interaction not mediated or directed by a facilitator or teacher, but more indirectly known through experience (Sternberg \& Caruso, 1985). Active engagement in constructing knowledge from experience informs personal values and ethics, creating "tacit knowledge" (Kuhn, 1962, p. 191) that can shape and awaken a shift in thinking, a paradigmatic peep hole into a new encounter. My arts-based research processes, visualized in this article, tacitly address knowledge development by the manipulation of materials stemming from contemplative engagement and decision making, that, in turn, construct meaningful encounters.

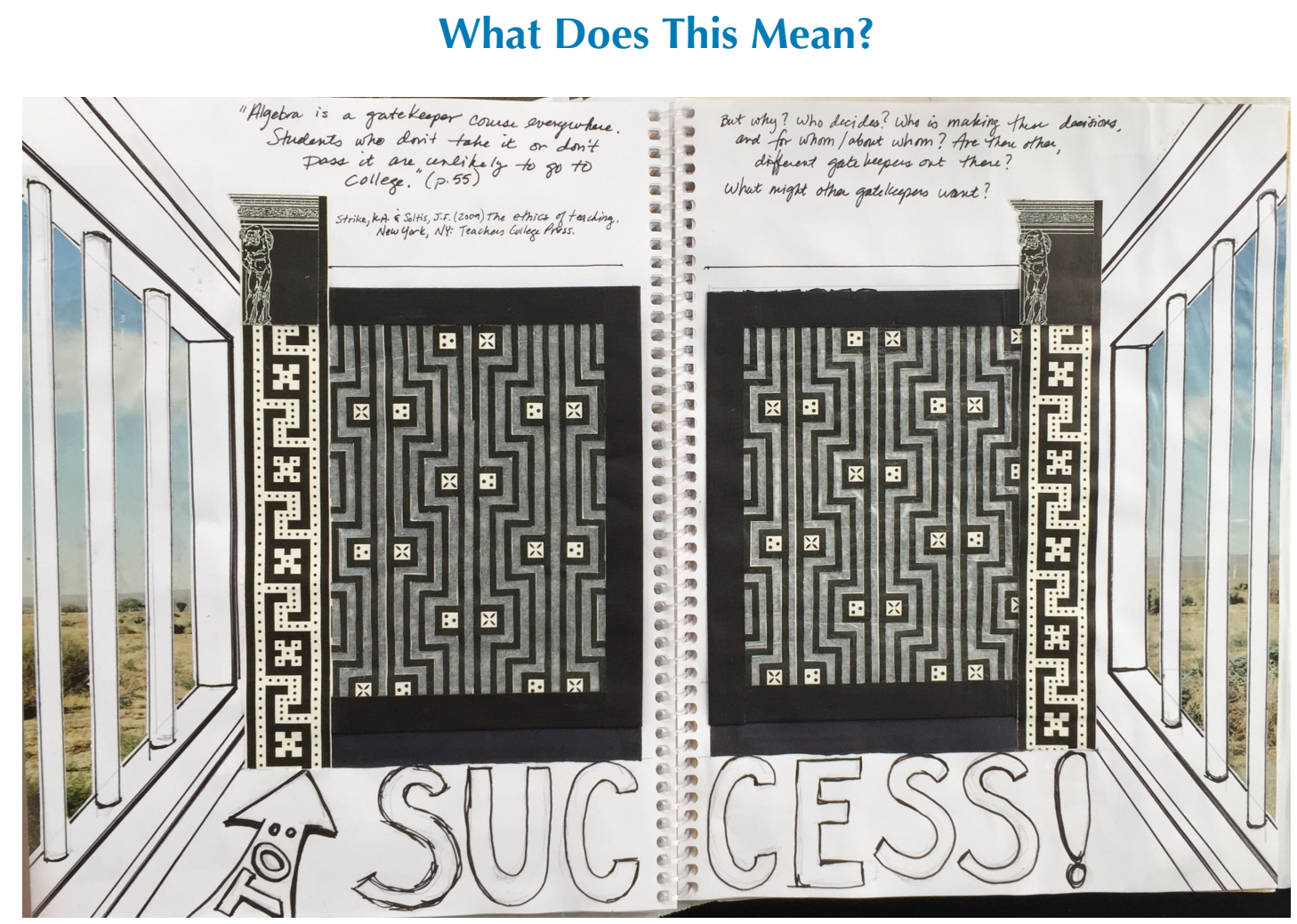

Fig. 5: Algebra. The gatekeeper to success. March 2018, mixed media collage on paper (gates open \& close), 16 x 11 in.

How did algebra become so powerful, with a godlike presence in our schools? A policy that both allows and restricts entry depending on who approaches the gates, may negate equity. Could there be another way? Another set of gatekeepers perhaps? Of course, there could be, but who tends those gates, beholden to whom, is also worth pondering.

Each new encounter has the potential to foster meaning: new words, ideas, or theories can create opportunities toward knowing. A bank of words (see section 2/Figure 2) as a basis for contemplation in arts-based research can provide a location for intentional meaning to form tacitly. However, if new encounters have a directive that prescribes meaning, any potential to acquire knowing may be restricted or cordoned off, disabling potential learning. The process of interpreting meaning, out of words, theories, or ideas, can enable learning and eventual knowing by ascribing intent through tacit processes of knowing. The words presented for rabbit-hole investigation above, are ideas awaiting formulation and 
interpretation. Embedded in those words are texts needing elucidation as reference points in a research agenda. A hermeneutic approach to interpretation that Hammersley (2012) outlines, links interpretivism with the shaping of beliefs and, from there, toward "interpreting texts" (p. 4). Past experiences will undoubtedly underpin interpreted meaning, but new research might affect and further inform previously embodied definitions, expanding the potential for interpretation. As experiences expand, so does context. Context is formed from conditions that develop out of interactions both public and private, in a mingling of symbolic interactionism: meaning is ascribed to things or concepts based on social interactions and as interpreted through individual and social encounters (Blumer, 1969). For example, if an art teacher asked a group of students to draw a chair, the resulting images could represent myriad interpretations of the word "chair," and if this task were assigned through a global learning platform, then the outcomes may prove even more interpretive and diverse. Human interactions and social constructs give meaning to ideas, things, and places, and individuals bring understanding as developed through engagement within social groups. Within social interactionism, meaning, language, and thinking all combine to help shape how individuals come to know or to assert connotation to the objects and ideas they encounter (Aksan, Kisac, Aydin, \& Demirbuken, 2009); social interaction acts as a building block for interpretation and meaning making. As described by Aksan and colleagues (2009) in their study and presentation on symbolic interaction theory:

meaning is created as a result of the interaction between people and meaning allows people to produce some of the facts forming the sensory world. These facts are related to how people form meaning. Thus, fact consists of the interpretation of various definitions. (p. 903)

Interpretation of facts, however, can result in a misrepresentation of reality if what one is interpreting as facts are opinions or beliefs meant to stoke a soapbox position, an entrenched canon, or a situation based in personal dogma, feelings, or associations. Some revisionist history, as seen in textbook publications, aimed at quieting accountability, for example, can result in the presentation of ideologies or political biases as truth or fact. If the social interaction is diverse, however, then an interpretation of sign and symbol systems stands a better chance of ascribing truthful meaning to encounters. This, in turn, can provide opportunities toward growth and appreciation for the interconnectedness of symbols, ideas, or connotations and context.

Interconnected and intertextual learning can happen across multiple sign systems or when literacy is shared through a transdisciplinary blending of symbolic interaction. Discipline-specific language learning is critical for appreciating distinct vocabularies that support and define individual contexts for learning, such as science-, art-, and mathematics-specific vocabulary. The processes for understanding and knowing the language or vocabulary of a field is vital for interaction within a discipline and between the participants engaged in that discipline. For example, language arts have traditionally focused on verbal pathways for teaching and learning in that field and tend to construct learning through a "verbocentric" (Leland \& Harste, 1994 , p. 337) lens, rather than building a transdisciplinary method of learning, engaging multiple sign systems as pathways for knowing. Fostering a methodology of literacy that encompasses and supports investigation within and between literacies can characterize what Leland and Harste describe as an idea of "whole literacy" (p. 344), or a process of becoming that is mediated contextually via a multisystemic approach to literacy. 
Coming to know language based on signs from various textual sources, can provide multiple entry points for engagement with texts that develop out of experimentation, leading toward a process of subjective knowing.

Subjective knowing is a perceptive process of learning that Heron and Reason (1997) define as "critical subjectivity" along the following pathways: "experiential, presentational, propositional, and practical" (p. 280). Subjective knowledge originates in experiences (with others, materials, processes) and reveals itself in a form symbolizing that experience (visually, dialogically, aurally). The presentation of the experiences and the demonstration of understanding through experiences completes the critically subjective encounter. It is in the sharing or dissemination phases of gleaned knowledge where impacts toward paradigm change can grow, not only for individual growth and development but for social growth as well. This process is supported by critical research theory and, according to Hammersley (2012), this theory endeavors to examine sociocultural histories as constructs leading to "social division" (p. 7). By revealing sites of division, this theory aims to locate "causes and consequences" (p. 7) of inequity that can be addressed through action that may lead toward raised social justice consciousness. Such an awareness could occur through interconnected dialogue, supported by multitextual interaction that reveals context as a bridge between ways of knowing through dialogic encounters. Building on the tenets of dialogism as defined and articulated by Bahktin (Holquist, 2002), critical theory and research aims to alter and reshape traditional dialogue from a hierarchical perspective to one emphasizing shared use, equity, and participatory input, where voices are heard and recognized equally: enhanced critical consciousness (Freire, 2011) through critical subjectivity as shared by means of utterances and interpretations.

But what happens when there is a lack of equity forged by hierarchical means? In Figure 5, I reflected on a text passage by Strike and Soltis (2009) where the authors discuss a case study involving a student struggling to pass high school algebra. In that passage, algebra is described as the gateway course to master for success (p. 55), especially for entry into college. As an arts-based researcher and educator, I wondered why this was the case and considered the potential inequities that might resonate within such a pronouncement. I deliberated on my own personal struggles with algebra and used that reflection to imagine a visual compositional response.

In Algebra. The gatekeeper to success, I imagined a space, a room with barred windows, created in a one-point perspective, leading to a set of gates. The interior space is drawn in black pen with cutout sections between the bars to reveal a collage of a vast landscape outside the room. On the floor leading to the gates are the words, "to success!" written in pen, and above the gates is the passage from Strike and Soltis (left side), accompanied by my research queries (right side). The gates are constructed of paper with sections cut away and a piece of tracing paper laid behind. A column adorns each side of the gates, bearing an antiquity-like figure supporting a Doric-like column top. What Figure 5 cannot reveal, however, is that the gates in this composition open on an image of the word "Algebra" written in chalk on a black surface, surrounded by various algebraic equations. The gates open, not onto the vast landscape as depicted through the barred windows, but onto algebra, in word and in problem.

As an arts-based research process, my intent in creating this image was to both reveal hierarchies in place in educational systems and the confinement that such hierarchies place on individual learners. That, in turn, led to the following questions: What policies and decisions, made over time, granted the 
gatekeeper position to algebra? Who made the policies and decisions, and whom are these policies and decisions made for? Perhaps not all learners that arrive at these gates approach them from the same equitable circumstances, as argued in the theories of Paulo Freire: oppressive criteria that inherently disadvantage some groups over others. This image postulates questions related to dialogue regarding social division in educational settings. It is an attempt to illustrate a research process based on visualizing research questions for deeper reflection and symbolism: a first step toward critical subjectivity, reflexively locating myself within a process of coming to know.

This section and the accompanying image in Figure 5, pondered several theoretical frameworks for constructing meaning, including interpretation, symbolic interaction, critical subjectivity, dialogue, language, and utterances. These frameworks or ideas influence pathways toward knowing that nest within a process of being, coined by Bakhtin as "ideological becoming" (Bakhtin, 1981; Ball \& Freedman, 2004), relating to the development of knowing and understanding over time, never fixed, always arriving. If a process of knowing exists along such a continuum, and becoming is a state of renewal and reemergence, what might this progression suggest for an artist/researcher/teacher seeking a path toward embodied knowing?

\section{Where Might These Meanderings Lead?}

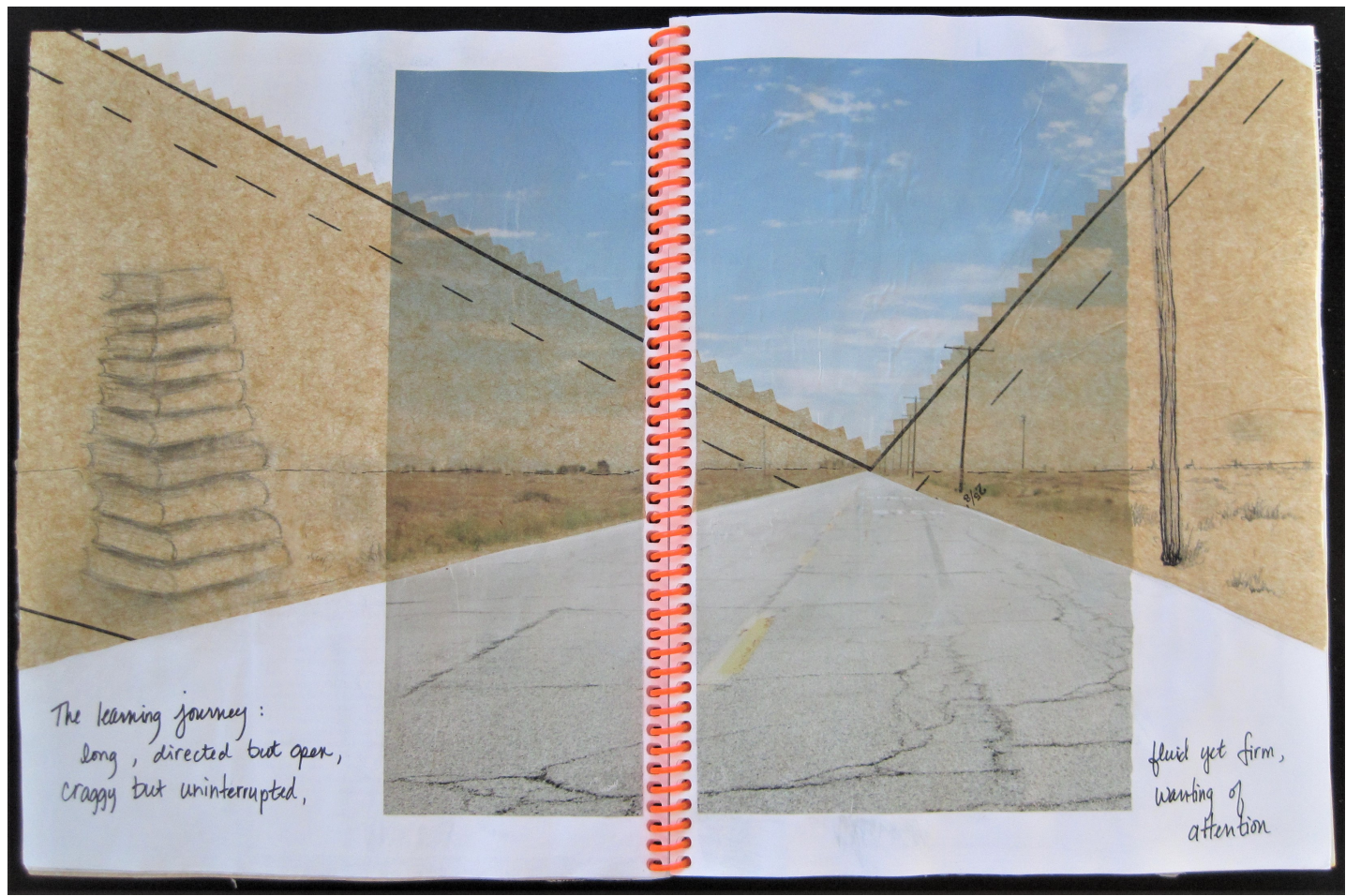

Fig. 6: The learning journey (which way is Knowing?). March 2018, mixed media collage on paper, $16 \times 11$ in.

Setting off down a path will cause undulations, disturbances to flow no matter how predictable your intended path appears. Your response to the shifts in terrain can enlighten and illuminate your journey, revealing a reflexive practitioner of mindful research praxis. 
The path to now has been long, eventful, and productive, though still becoming. In sharing this story, as an artist/researcher/teacher, my aim was to express literal and figurative connections to a way of knowing gleaned through arts-based research and reflexive praxis. Along the way, I hoped to illustrate that knowing can come from an iterative process of reflection that may alter paradigms, but through alteration, new or emergent pathways may develop, leading toward embodied knowing. My original map, once adequate, needs continual modification, revision, and reassessment: a revised plan revealing evidence of change. Invested within this change process, any adjustments become a reflexive act of acquiring knowledge while in motion (Schön, 1983), acting with and within that knowledge to uncover and reveal a self that is ready for understanding, for growth, and for awareness.

As I traverse a journey through these experiences, the route forward appears less chaotic, and there may even be the semblance of a strategy to navigate the terrain, a map sifting and realigning in real time. I am the bricoleur of my experiences (Lévi Strauss, 1962) as they develop out of a newly realized paradigm of actionable knowledge. Critical reflection and subjectivity, shared encounters, and awareness in practical action provide suitable boundaries for resistance and persistence. Reflection demands careful attention to practice, to be mindful of personal bias or potential prejudice that can stymie progress: reflection cannot only exist in the abstract, it needs to be made real and, in doing so, make it tangible, evidentiary, and committed (Freire, d'Ambrosio, \& Mendonça, 1997; hooks, 1993).

As a researcher, reading academic research articles or studies is an essential practice, though, as an artsbased researcher my confidence level fluctuates from comfort and ease within qualitative research readings, to discomfort and unease within quantitative readings, especially those quantitative studies replete with ample statistical information and related equations. The image in Figure 6 began with a magazine image showing a paved road receding into a vanishing point within a vast and barren, big-sky landscape. I chose to accentuate the vanishing point with triangles cut from dress pattern paper and then completed the photographic image with my own drawn imagery, including a pile of books, representing knowledge, on the side of the road. Though the road appears paved, it is far from smooth. This notion, the cracked and jagged road, often full of potholes, is how I have always visualized reading quantitative articles: the statistical equations, numbers, tables, and the daunting number of citations interrupt, deter, and even stop me from freely reading the text. The road, then, becomes less easy to navigate, less willing to reveal its secrets or findings. However, I did conceive of the image as a pathway toward knowing, and though the process may require me to slow down, seek assistance, or take a break, the road does go on and I can choose to commit to its fluctuations in a reflexive inquiry process.

Visual and experimental inquiry processes can shape the abstract toward form, design, and consciousness. Arts-based research and exploration can continue to map future terrain as meaningful contributions to the academic canon, while supporting an iterative learning process as a location for understanding within reflexive praxis. Reflecting, again, upon Dewey (1920), I desire to work as an "experimental thinker" (Simpson, 2006, p. 45) incorporating generative ideas into a learning process and to strive toward "educational agency" as a "source of teaching and learning, whether intentional or otherwise" (p. 143). To be a source and resource, a well, for teaching and learning, is where I am headed as a researcher and arts-based practitioner: deliberate in action, word, and habitual mindfulness. 
Maxine Greene (1978) considered the idea of reflexivity as an action in communication with a landscape of other learners, in dialogic praxis as teachers:

Teaching involves deliberate and purposeful action carried on by a live human being who can reflect upon what he or she is doing, who is not an automaton, but self-conscious and self-aware. Teaching involves such a person in interactions with (or dialogue with) a variety of other live human beings. These others are, by means of the dialogue, to be enabled to learn how to learn. Or, to put it somewhat differently, they are to be enabled consciously to enter into the learning process, to choose to become members of a particular learning community. (p. 247)

Choosing to participate as a reflexive artist/researcher/teacher within a community of other educators as learners, or any others willing to become through learning, is an intentional activity as a praxis of becoming and knowing. The image in Figure 6 shows a distant point, unmarked and out-of-view. This is an intentional act: revealing that the process of knowing and becoming continues onward, beckoning an arrival that is always a bit further in the distance. My arts-based reflection illustrations reveal my process for imagining what research and a researcher might look like, claiming an identity imbued with reflexivity and embodied awareness through knowing and eventual becoming.

\section{Note}

1. All images are copyright of the author and produced in studio practice by the author.

\section{References}

Aksan, Ni., Kisac, B., Aydin, M., \& Demirbuken, S. (2009). Proceedings from world conference on educational sciences: Symbolic interaction theory. Procedia Social and Behavioral Sciences, 1, 902-904.

Bakhtin, M. M. (1981). The dialogic imagination: Four essays. Translated by M. Holquist and C. Emerson. Austin, TX: University of Texas Press.

Ball, A.F., \& Freedman, S.W. (2004). Bakhtinian perspectives on language, literacy, and learning. New York, NY: Cambridge University Press.

Blumer, H. (1969). Symbolic interactionism: Perspective and method. Englewood Cliffs, NJ: Prentis Hall, Inc.

Cambridge Dictionary. (2018).

Retrieved from https://dictionary.cambridge.org/us/dictionary/english/can-t-see-the-wood-for-the-trees

Crotty, M. (1998). The foundations of social research: Meaning and perspective in the research process. Thousand Oaks, CA: Sage Publications.

Delacruz, E., \& Dunn, P. (1996). The evolution of discipline-based art education. Journal of Aesthetic Education, 30(3), 67-82. doi:10.2307/3333322

Dewey, J. (1920). Reconstruction in philosophy. New York, NY: Henry Holt and Company. 
Dewey, J. (1934). Art as experience. New York, NY: Penguin Group, Inc.

Eisner, E. (2012). Art and knowledge. In A.L. Coles \& G. Knowles (Eds.), Handbook of the arts in qualitative research: Perspectives, methodologies, examples, and issues (pp. 3-13). Thousand Oaks, CA: Sage Publications, Inc.

Encyclopedia of Art. (2018). Retrieved from http://www.visual-arts-cork.com/postmodernism.htm

Freire, P. (2011). Pedagogy of the oppressed (Rev. ed.). New York, NY: Continuum International Publishing Group.

Freire, P., d'Ambrosio, U., \& Mendonça, M.d.C. (1997). A conversation with Paulo Freire. For the Learning of Mathematics, 17(3), 7-10.

Girl Scouts of the United States of America. (1955). Girl scout handbook: Intermediate edition. New York, NY: The Girl Scouts of the U.S.A.

Glass, M.R. (2015). Teaching critical reflexivity in short-term international field courses:

Practices and problems. Journal of Geography in Higher Education, 39(4), 554-567, doi:10.1080/03098265.2015.1084610

Greene, M. (1978). Landscapes of learning. New York, NY: Teachers College Press.

Hammersley, M. (2012). Methodological paradigms in educational research. British Educational Research Association on-line resource. Retrieved from https://www.bera.ac.uk/researchersresources/publications/methodological-paradigms-in-educational-research

Heron, J., \& Reason, P. (1997). A participatory inquiry paradigm. Qualitative Inquiry, 3(3), 274-294.

Holquist, M. (2002). Dialogism: Bakhtin and his world. London: Routledge.

hooks, b. (1993). bell hooks speaking about Paulo Freire: The man, his work. In P. McLaren \& P. Leonard (Eds.), Paulo Freire: A critical reader (pp. 146-154). New York, NY: Routledge.

Knabb, K. (Trans.). (1995). Theory of the dérive by Guy Debord. Retrieved from https://www.cddc.vt.edu/sionline/si/theory.html

Kuhn, T. (1962). The structure of scientific revolutions. Chicago, IL: University of Chicago Press.

Leavy, P. (2015). Method meets art: Arts-based research practice. New York, NY: The Guilford Press.

Leland, C.H., \& Harste, J.C. (1994). Multiple ways of knowing: Curriculum in a new key. Language Arts, 71(5), 337-345.

Lévi Strauss, C. (1962). The savage mind. Chicago, IL: University of Chicago Press.

McGarry, K. (2018). Making partnerships with STEAM. Art Education, 71(2), 28-34.

Ramberg, B. (Spring 2009). Richard Rorty. The Stanford Encyclopedia of Philosophy (Spring 2009

Edition), Edward N. Zalta (Ed.). Retrieved from https://plato.stanford.edu/entries/rorty/

Rolling, Jr., J.H. (2013). Arts-based research. New York, NY: Peter Lang Publishing, Inc.

Schön, D. A. (1983). The reflective practitioner: How professionals think in action. New York, NY:

Basic Books. 
Simpson, D.J. (2006). John Dewey: Primer. New York, NY: Peter Lang Publishing, Inc.

Sternberg, R.J., \& Caruso, D.R. (1985). Practical modes of knowing. In E. Eisner (Ed.), Learning and teaching: The ways of knowing (pp. 133-158). Chicago, IL: University of Chicago Press.

Strike, K.A., \& Soltis, J.F. (2009). The ethics of teaching (5th edition). New York, NY:

Teachers College Press.

TED. (2014). Cindy Foley: Teaching art or teaching to think like an artist? [Video file]. Retrieved from https://youtu.be/ZcFRfJb2ONk.

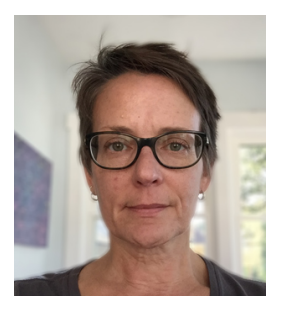

Karen McGarry is a visual artist/educator presently pursuing a $\mathrm{PhD}$ at the University of Cincinnati (UC), OH, in Educational Studies. She holds an MFA with a minor in Women's Studies from the University of Illinois at Chicago and an MAAE with licensure from UC. Prior professional experience includes K-12 visual arts and humanities classroom teaching and adjunct experience with instruction in teacher education at UC, California State University Long Beach, California Institute of the Arts, and the Art Academy of Cincinnati. 